\title{
Growth Mechanisms of Silica-Modified Polyaniline and Zinc Oxide Nanostructures on Glass Substrates
}

\author{
Christine Adelle L. Rico, Arnold C. Alguno, Jess E. Gambe, Rolando T. Candidato, Majvell Kay G. \\ Odarve, Bianca Rae B. Sambo, Filchito Renee G. Bagsican, and Reynaldo M. Vequizo
}

\begin{abstract}
Silica-modified polyaniline (SM-PANI) thin films were prepared on glass substrates by oxidative polymerization. Zinc oxide $(\mathrm{ZnO})$ nanostructures were grown on top of SM-PANI thin films by chemical bath deposition using zinc sulphate and varying concentrations of ammonium hydroxide. SM-PANI and $\mathrm{ZnO}$ nanostructures were characterized by scanning electron microscopy (SEM). SEM images revealed surface morphology of the nanostructures: SM-PANI forming rod-like nanostructures, and $\mathrm{ZnO}$ forming sea-urchin-like nanostructures grown on top of SM-PANI. Characterization results also revealed that ammonium hydroxide concentration can modify $\mathrm{ZnO}$ nanostructures grown on top of SM-PANI. For $1 M$ concentration, hexagonal rod-like SM-PANI and sea-urchin-like $\mathrm{ZnO}$ nanostructures were present; for $\mathbf{3 M}$ concentration, flake-like $\mathrm{ZnO}$ nanostructures were grown with deformed rod-like SM-PANI. This mechanism can be explained via competition between growth of SM-PANI and $\mathrm{ZnO}$ nanostructures, and etching process during the chemical bath deposition of $\mathrm{ZnO}$ at different concentrations of ammonium hydroxide.
\end{abstract}

Index Terms-Ammonium hydroxide, nanostructures, silica-modified polyaniline, zinc oxide.

\section{INTRODUCTION}

In the last few decades, since the rise of nanotechnology initiative, nanostructures have been widely developed as a leading edge in science and technology. Reducing the size of the materials in their nanometer scale provides opportunities to further study their novel electrical, mechanical, chemical and optical properties [1]. The synthesis of nanostructures is a growing field of research for various important applications with emphasis on developing nanostructures via low cost processes [2]. Among the nanostructures that have been studied intensively, $\mathrm{ZnO}$ has become the most active area of research and is dubbed to be the most important nanomaterial after the carbon tubes [3]. This is due to the unique properties of $\mathrm{ZnO}$ such as a wideband gap of $3.37 \mathrm{eV}$ suitable for short wavelength optoelectronic applications, and high exciton

Manuscript received January 12, 2013; revised March 18, 2013. This work was supported in part by the Department of Science and Technology Accelerated Science and Technology Human Resource Development Program and the Commission on Higher Education - Philippine Higher Education Network in the Philippines.

C. A. L. Rico is with the Materials Science Laboratory, Physics Department, College of Science and Mathematics, Mindanao State University- Iligan Institute of Technology, Tibanga, Iligan City, 9200 Philippines (e-mail: rico.adelle@gmail.com).

A. C. Alguno, J. E. Gambe, R. T. Candidato, M. K. G. Odarve, B. R. B. Sambo, F. R.G. Bagsican, and R. M. Vequizo are with the Department of Physics, College of Science and Mathematics, Mindanao State UniversityIligan Institute of Technology, Tibanga, Iligan City, 9200 Philippines. energy of $60 \mathrm{meV}$ that can ensure efficient excitonic emission at room temperature [1]. Furthermore, $\mathrm{ZnO}$ can easily form a diverse group of growth morphologies such as nanocombs, nanorings, nanobelts, nanowires among others, which have the potential for catalysis or solar cell applications due to their high specific surface area and reactivity [4].

Recently, hybrid nanocomposites have been developed to enhance the advantages of conducting organic polymers (COPs) by combining it to an inorganic material (such as $\mathrm{ZnO}$ ). The multifunctionality observed from hybrid nanocomposite materials empowers their application in a wide variety of energy-related devices particularly solar cells [5]. The key factor behind the operation of hybrid nanocomposites is the close contact between the inorganic material and COPs [6].

For COPs, polyaniline (PANI) is the most promising owing to its high conductivity, environmental stability and ease to prepare [7]. Mechanisms of the formation of PANI nanostructures have recently been reviewed and assessed for various applications as COP [8]. PANI has three individual forms - leucoemeraldine, emeraldine, and pernigraniline. The protonated emeraldine is obtained as a product of polymerization. Its conversion to an emeraldine base after treatment with alkali is one of the most famous reactions of PANI: the reduction of emeraldine to leucoemeraldine and the oxidation to pernigraniline [9]. Of the three forms, PANI in its emeraldine form is the most fabricated because it has the most conductive state with its environmental stability, and straightforward fabrication.

Furthermore, PANI is incorporated with silica, which acts as limiting director for growth of PANI nanostructures on the substrate. Study shows that silica enhances the agglomeration of polyaniline on the substrate [10], [11]. The addition of colloidal silica into the polymerization mixture of aniline has been explored by Stejskal, et al. [12] to prevent the occurrence of macroscopic agglomeration that led to formation of thinner PANI films (see Fig. 1.). When PANI is deposited in the presence of silica, the resulting PANI and silica nanocomposite possessed higher surface areas, larger redox charge capacities, and higher doping levels, thus enhancing its optical properties [10], [12].

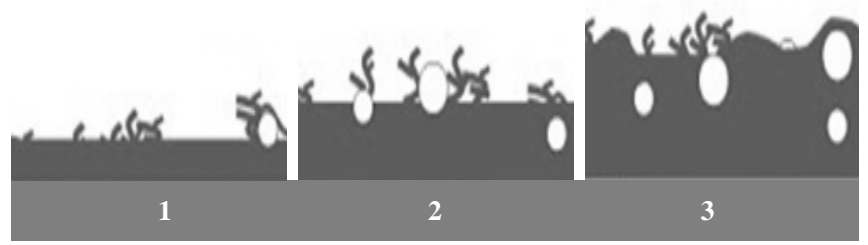

Fig. 1. Growth mechanism of PANI modified with colloidal silica. 
In this study, hybrid nanocomposites have been fabricated by combining SM-PANI and ZnO. Oxidative polymerization of aniline with ammonium peroxidisulphate (APS) as an oxidizing agent was carried out to synthesize SM-PANI nanostructures. On the other hand, chemical bath deposition was employed to synthesize $\mathrm{ZnO}$ nanostructures on top of SM-PANI using zinc sulphate and varying concentrations of ammonium hydroxide.

\section{EXPERIMENTAL PROCEDURES}

\section{A. Preparation of Glass Substrates}

SM-PANI and $\mathrm{ZnO}$ nanostructures were grown on rectangular glass slides with dimension $26 \mathrm{~mm} \times 76 \mathrm{~mm} \times$ $1 \mathrm{~mm}$. Glass slides which serve as substrates were washed with acetone, ethanol, 1M hydrochloric acid, and distilled water. Acetone removes oils and inorganic substances present in the substrate, while the ethanol and $1 \mathrm{M}$ hydrochloric acid remove the residues of acetone and the oxides in the substrates, respectively. The substrates are then dried at room temperature after cleaning.

\section{B. Synthesis of Silica-Modified Polyaniline Nanostructures}

Synthesis of silica-modified PANI nanostructures is carried out by the oxidative aniline polymerization and incorporation of silica extracted from rice husks ash. To obtain the best result of PANI, a stoichiometric peroxidisulphate/aniline ratio of 1.25 is maintained. This minimizes the presence of residual aniline. To achieve the stoichiometric ratio, of pure liquid aniline and $12 \mathrm{M} \mathrm{HCl}$ is dissolved in distilled water. Upon achieving homogeneity between aniline and $12 \mathrm{M} \mathrm{HCl}$, silica powder from rice husks is added to the solution.

Another solution is prepared by dissolving APS in distilled water. Both solutions are left for an hour at room temperature. The solutions are then rapidly mixed inside the beaker. The substrates are placed inside the beaker as reaction vessel where polymerization is carried out for five hours. When the post-polymerization is achieved, indicated by the rapid decrease of temperature after hitting the highest temperature, the substrates are immediately removed and washed with $0.2 \mathrm{M}$ hydrochloric acid and ethanol to remove the residual monomer, oxidants and its decomposition products; and to remove low-molecular-weight organic intermediates and oligomers, respectively [13]. The samples are then dried at room temperature.

\section{Synthesis of Zinc Oxide Nanostructures}

Chemical bath deposition is carried out to synthesize $\mathrm{ZnO}$ nanostructures. The ammonium zincate bath, used for deposition of $\mathrm{ZnO}$ is prepared by adding ammonium hydroxide ( $25 \%$ ammonia solution) to an aqueous solution of zinc sulphate $(\mathrm{ZnSO} 4 \cdot 7 \mathrm{H} 2 \mathrm{O})$ which will react to the chemical equation:

$$
\mathrm{ZnSO}_{4}+2 \mathrm{NH}_{4} \mathrm{OH} \rightarrow \mathrm{Zn}(\mathrm{OH})_{2}+\left(\mathrm{NH}_{4}\right)_{2} \mathrm{SO}_{4}
$$

where a white precipitate is formed. The ammonium zincate bath used for the deposition contains ammonium sulphate. It appears that while zincate precipitates as $\mathrm{ZnO}$ in presence of high concentration of water when dipped with hot bath, the sulphate goes into the solution to its high solubility in water as in the chemical equation:

$$
\left(\mathrm{NH}_{4}\right)_{2} \mathrm{ZnO}_{2}+\mathrm{H}_{2} \mathrm{O} \rightarrow \mathrm{ZnO}+2 \mathrm{NH}_{4} \mathrm{OH}
$$

The substrates are then synthesized at different concentrations of ammonium hydroxide for comparison (1M and $3 \mathrm{M}$ ). Ammonium hydroxide is added to distilled water. Another solution is prepared by mixing zinc sulphate powder with distilled water. The two solutions are then stirred in a beaker, placed in the bath, using a magnetic stirrer having a $360 \mathrm{rpm}$. After 30 minutes, the bath is heated, maintaining the temperature to $70^{\circ} \mathrm{C}$ for 5 hours. The procedure is carried out following the standard chemical bath deposition method [14]. After 5 hours, the substrates are then dried at room temperature.

\section{Characterization of SM-PANI and $\mathrm{ZnO}$ Nanocomposite}

The fabricated nanocomposites of were characterized with SEM (JEOL Model JSM-6510LA) for its surface morphology and elemental analysis.

\section{RESULTS AND DISCUSSION}

\section{A. Morphology of SM-PANI and ZnO Nanocomposites}

The morphologies of the nanocomposites produced from the oxidative polymerization of SM-PANI and chemical bath deposition of $\mathrm{ZnO}$ are shown in Fig. 2 and Fig. 3.

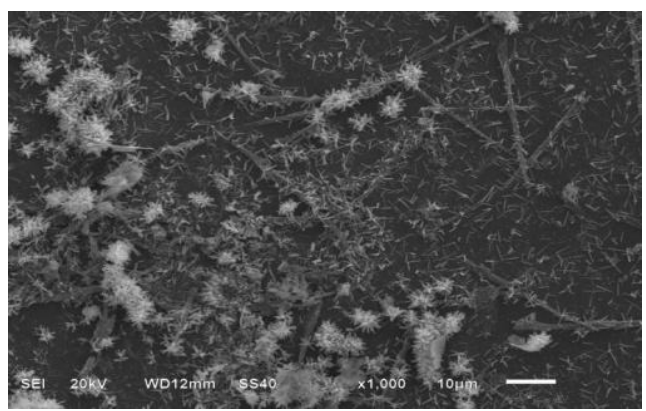

(a)

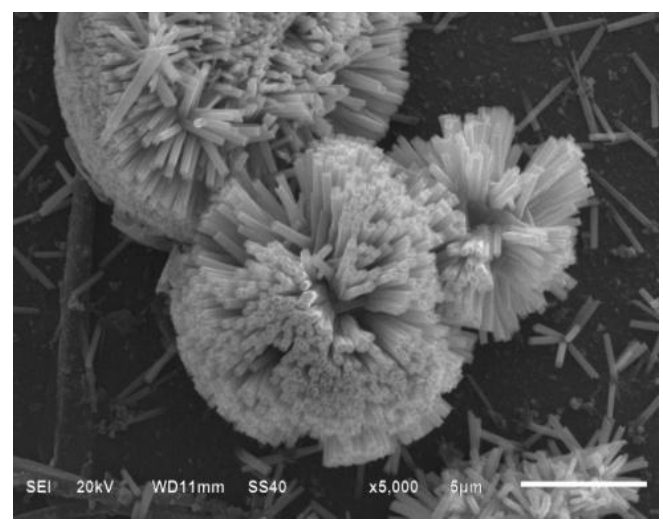

(b)

Fig. 2. SEM micrographs of SM-PANI and $\mathrm{ZnO}$ nanocomposites with $1 \mathrm{M}$ concentration of ammonium hydroxide at (a) higher magnification (1000x) and (b) lower magnification (5000x).

Fig. 2 shows the morphology of the nanocomposites at $1 \mathrm{M}$ 
concentration of ammonium hydroxide. SEM image reveals the presence of rod-like SM-PANI nanostructures and sea-urchin-like $\mathrm{ZnO}$ nanostructures.

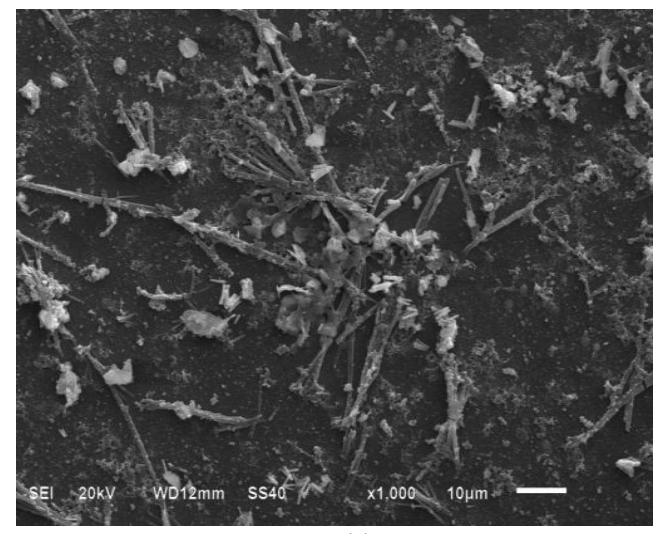

(a)

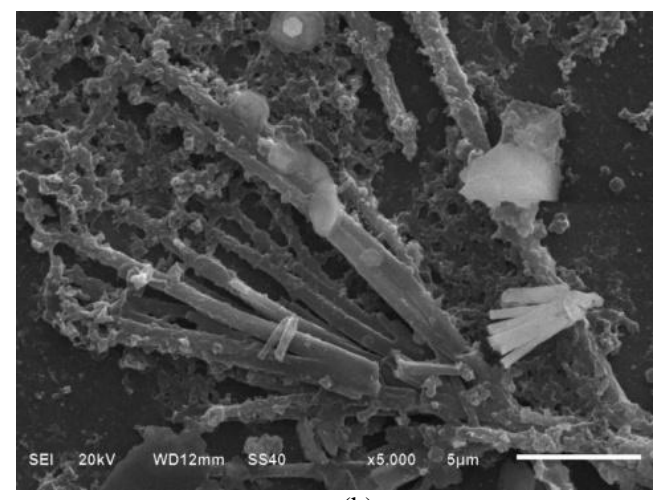

(b)

Fig. 3. SEM micrographs of SM-PANI and $\mathrm{ZnO}$ nanocomposites with $3 \mathrm{M}$ concentration of ammonium hydroxide at (a) higher magnification $(1000 x)$ and (b) lower magnification (5000x).

1) Morphology of SM-PANI and ZnO nanostructures in $1 M$ ammonium hydroxide

Instead of the formation of PANI precipitates on the substrates that usually leads to the formation of non-uniform agglomerates [15], the presence of dispersed silica produces PANI nanostructures. Furthermore, the morphology of SM-PANI indicates that there is an increase of surface area when silica particles are present in the polymerization of aniline which served as small adsorbing substrates initiating the growth of uniform particles in bulk polymerization. In the presence of $\mathrm{ZnO}$ nanostructures with $1 \mathrm{M}$ concentration of ammonium hydroxide, the morphology of SM-PANI indicates presence of rod-like nanostructures. The formation of SM-PANI rod-like nanostructures in the nanocomposite shows uniform agglomeration due to aniline oligomers which initiated the growth of PANI with silica.

On the other hand, $\mathrm{ZnO}$ nanostructures with $1 \mathrm{M}$ concentration of ammonium hydroxide are accumulated at the center (seed nuclei) and are grown on different direction forming sea-urchin-like nanostructure. Previous work reported that this sea-urchin-like structure is attributed to the $\mathrm{Zn}(\mathrm{OH})_{2}$ formed after mixing the $\mathrm{ZnSO}_{4}$ and $\mathrm{NH}_{4} \mathrm{OH}$ which served as the seed nuclei on the substrate [16], [17].

\section{2) Morphology of SM-PANI and ZnO nanostructures in} $3 M$ ammonium hydroxide

Fig. 3 shows the morphology of SM-PANI and $\mathrm{ZnO}$ nanocomposites with $3 \mathrm{M}$ concentration of ammonium hydroxide. Instead of producing uniform rod-like nanostructures of SM-PANI, the nanostructures are deformed. There is uneven agglomeration of structures on the substrates. On the other hand, $\mathrm{ZnO}$ nanostructures apparently became flake-like which can be attributed to the etching effect of ammonium hydroxide. With $3 \mathrm{M}$ concentration of ammonium hydroxide, the surface of the substrates is covered with flake-like structures which grow randomly in different directions.

\section{B. Etching Process of Ammonium Hydroxide on SM-PANI} and $\mathrm{ZnO}$ Nanocomposites

The diameter of nanostructures increases $1 \mu \mathrm{m}$ as the concentration of ammonium hydroxide increases [18]. The nanostructures composing the sea-urchin-like $\mathrm{ZnO}$ is attributed to the increase of ammonium hydroxide concentration which can be explained in the following chemical reaction:

$$
\begin{aligned}
& \mathrm{ZnSO}_{4}+2 \mathrm{NH}_{4} \mathrm{OH} \rightarrow \mathrm{Zn}(\mathrm{OH})_{2}+\left(\mathrm{NH}_{4}\right)_{2} \mathrm{SO}_{4} \\
& \mathrm{Zn}(\mathrm{OH})_{2}+2 \mathrm{H}_{2} \mathrm{O} \rightarrow \mathrm{Zn}(\mathrm{OH})_{4}+2 \mathrm{H}^{+} \\
& \mathrm{Zn}(\mathrm{OH})_{4} \rightarrow \mathrm{ZnO}+\mathrm{H}_{2} \mathrm{O}+2 \mathrm{OH}^{-}
\end{aligned}
$$

The $\mathrm{ZnO}$ will react to water producing $\mathrm{Zn}(\mathrm{OH})_{4}$ with zinc ion which supply free $\mathrm{Zn}^{2+}$ ions to combine with $\mathrm{O}^{2-}$ to form $\mathrm{ZnO}$ as shown in Equation (3). As the amount of zinc hydroxide increases, the zinc complex $\mathrm{Zn}(\mathrm{OH})_{4}$ with zinc ion also increases. This decreases the number of $\mathrm{Zn}^{2+}$ ions that will combine to $\mathrm{O}^{2-}$ to form nanostructures. At higher concentration, there is an excess of $\mathrm{OH}^{-}$on the solution that attacks the nanostructures on the substrates.

\section{CONCLUSION}

SM-PANI and $\mathrm{ZnO}$ nanostructures were successfully grown on glass substrates. SM-PANI nanostructures were synthesized via oxidative polymerization; $\mathrm{ZnO}$ nanocomposites via chemical bath deposition. SEM images revealed SEM images revealed surface morphology of the nanostructures: SM-PANI forming rod-like nanostructures, and $\mathrm{ZnO}$ forming sea-urchin-like nanostructures grown on top of SM-PANI. Characterization results also revealed that ammonium hydroxide concentration can modify $\mathrm{ZnO}$ nanostructures grown on top of SM-PANI. For $1 \mathrm{M}$ concentration, hexagonal rod-like SM-PANI and sea-urchin-like $\mathrm{ZnO}$ nanostructures were present; for $3 \mathrm{M}$ concentration, flake-like $\mathrm{ZnO}$ nanostructures were grown with deformed rod-like SM-PANI. This mechanism can be explained via competition between growth of SM-PANI and $\mathrm{ZnO}$ nanostructures, and etching process during the chemical bath deposition of $\mathrm{ZnO}$ at different concentrations of ammonium hydroxide. 


\section{ACKNOWLEDGMENT}

Authors would like to thank CHED-PherNet for partial support in this work. CALR would to acknowledge the Department of Science and Technology- Science Education Institute in the Philippines for the scholarship grant.

\section{REFERENCES}

[1] Z. L. Wang, "Zinc oxide nanostructures: growth, properties and applications," Journal of Physics: Condensed Matter, vol. 16, 2004, pp. $829-858$

[2] S. N. Alam, "SEM, EDX \& XRD of Zinc Oxide Nanostructures Synthesized by Zinc Oxidation," Ph.D. dissertation, Department of Metallurgical and Materials Engineering, National Institute of Technology-Rourkela, Rourkela, Orissa, India, 2012.

[3] A. R. Bari, M. D. Shinde, V. Deo, and L. A. Patil. (January 2009). Effects of solvents on particle morphology of nanostructured $\mathrm{ZnO}$. Indian Journal of Pure and Applied Physics. vol. 47. pp. 24-27. [Online]. $\quad$ Available: http://nopr.niscair.res.in/bitstream/123456789/3142/1/IJPAP\%2047(1 $\%$ 2024-27.pdf

[4] R. Chena, C. Zoua, X. Yana, A. Alyamanib, and W. Gao. (January 2011). Growth mechanism of $\mathrm{ZnO}$ nanostructures in wet-oxidation process. Elsevier: Thin Film Solids. vol. 519, Issue 6. pp. 1837-1844. [Online]. Available: http://dx.doi.org/10.1016/j.tsf.2010.10.012.

[5] M. Lira-Cantú and P. Gómez-Romero, Next-Generation Hybird Nanocomposite Materials, Spain, 2009, pp. 289-319.

[6] S. Gunes, "Nanostructured Electrodes From Inorganic Materials for Hybrid Solar Cells," Ph.D. dissertation, Institute for Organic Solar Cells, Johannes Kepler Universität Linz, 2006.

[7] J. Stejskal, O. Quadrat, and I. Sapurina. (August 2002). Polyaniline-coated silica gel. European Polymer Journal. Vol. 38. pp. 631-637. [Online]. Available: www.elsevier.com/locate/europolj.

[8] D. Li, J. Huang, and R. B. Kaner, "Polyaniline Nanofibers: A Unique Polymer Nanostructure for Versatile Applications," in Accounts of Chemical Research, NanoSystems Institute, University of California, Los Angeles, California 90095-1569: ACS Publications, 2008, pp. $135-145$.

[9] J. Stejskal, I. Sapurina, and M. Trchová, "Polyaniline nanostructures and the role of aniline oligomers in their formation," Progress in Polymer Science, vol. 35. pp. 1420-1481, July 2010.

[10] A. Riede, M. Helmstedt, I. Sapurina, and J. Stejskal, Journal of Colloid and Interface Science, no. 248, 2002, pp. 413-418

[11] A. Riede, M. Helmstedt, V. Riede, J. Zemek, and J. Stejskal: American Chemical Society, Langmuir, no. 16, 2000, pp. 6240-6244.
[12] J. Stejskal and R. G. Gilbert, Pure Appl. Chem, vol. 74, no. 5, pp. $857-867,2002$

[13] W. Wang and E. Schiff, Applied Physics Letters, vol. 91, 2007.

[14] K. Quilaton, "Synthesis and structural, morphological and infrared characteristics of chemically prepared $\mathrm{ZnO}$ thin films and powders," M.S. Thesis, Mindanao State University- Iligan Institute of Technology, Tibanga, Iligan City, Philippines. 2009.

[15] A. Riede, M. Helmstedt, V. Riede, J. Zemek, and J. Stejskal, "In Situ Polymerized Polyaniline Films. 2. Dispersion Polymersion of Aniline in the Presence of Colloidal Silica," Langmuir, vol. 16, 2000, pp. 6240-6244.

[16] J. Stejskal and R. G. Gilbert, Pure Appl. Chem, vol. 74, no. 5, pp. $857-867,2002$

[17] N. Tabudlong, "Fabrication and Characterization of Chemically Deposited ZnO Thin Films on Amorphous silica and p-Si (100)," MS Thesis, Physics Dept., Mindanao State University- Iligan Institute of Technology, Iligan City, Philippines. 2008.

[18] R. Wahab, "The role of $\mathrm{pH}$ variation on the growth of zinc oxide," Applied Surface Science, vol. 255, 2009, pp. 4891-4896.

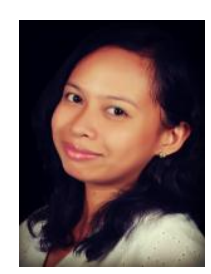

Christine Adelle L. Rico was born on March 7, 1986 in Pala-o, Iligan City, Philippines. She finished her Bachelor of Science in Physics degree in 2007 at Mindanao State University- Iligan Institute of Technology, Magna Cum Laude. She is currently pursuing her Masters of Science in Physics degree at the same university focusing on nanostructures for solar cell application. She is a member of the Samahang Pisika ng Visayas at Mindanao, a national Physics organization in the Philippines.

Arnold C. Alguno is a professor in the Department of Physics at Mindanao State University - Iligan Institute of Technology (MSU-IIT), Iligan City, Philippines. He finished his Doctor of Science in Physics at Tohoku University, Japan.

Jess E. Gambe and Rolando T. Candidato are an assistant Professors in the Department of Physics at MSU-IIT, Iligan City, Philippines. He finished his M.Sc. in Physics in the same university.

Majvell Kay G. Odarve, Bianca Rae B. Sambo, and Filchito Renee G. Bagsican are Instructors in the Department of Physics at MSU-IIT, Iligan City, Philippines.

Reynaldo M. Vequizo is a professor in the Department of Physics at MSU-IIT, Iligan City, Philippines. He finished his Ph.D. in Advanced Materials at Niigata University, Japan. 